\title{
Epigenetic control of mitochondrial cell death through PACS1-mediated regulation of BAX/BAK oligomerization
}

\author{
Daniella Brasacchio ${ }^{1,2,3}$, Amber E Alsop ${ }^{4,5}$, Tahereh Noori ${ }^{1,2}$, Mariam Lufti ${ }^{4,5}$, Sweta lyer ${ }^{4,5}$, Kaylene J Simpson ${ }^{2,6}$, Phillip I Bird ${ }^{7}$, \\ Ruth M Kluck ${ }^{4,5}$, Ricky W Johnstone ${ }^{\star, 1,8,9}$ and Joseph A Trapaniं ${ }^{\star, 1,2,9}$
}

PCAF and ADA3 associate within the same macromolecular complexes to control the transcription of many genes, including some that regulate apoptosis. Here we show that PCAF and ADA3 regulate the expression of PACS1, whose protein product is a key component of the machinery that sorts proteins among the trans-Golgi network and the endosomal compartment. We describe a novel role for PACS1 as a regulator of the intrinsic pathway of apoptosis and mitochondrial outer membrane permeabilization. Cells with decreased PACS1 expression were refractory to cell death mediated by a variety of stimuli that operate through the mitochondrial pathway, including human granzyme B, staurosporine, ultraviolet radiation and etoposide, but remained sensitive to TRAIL receptor ligation. The mitochondria of protected cells failed to release cytochrome $c$ as a result of perturbed oligomerization of BAX and BAK. We conclude that PCAF and ADA3 transcriptionally regulate PACS1 and that PACS1 is a key regulator of BAX/BAK oligomerization and the intrinsic (mitochondrial) pathway to apoptosis.

Cell Death and Differentiation (2017) 24, 961-970; doi:10.1038/cdd.2016.119; published online 6 January 2017

The intrinsic (mitochondrial) apoptosis signaling pathway is tightly regulated by the $\mathrm{Bcl}-2$ protein family. ${ }^{1}$ A key step involves the activation of either BAX or BAK to undergo major conformation change and oligomerization to form pores in the mitochondrial outer membrane (MOM). Non-activated BAK is constitutively anchored in the MOM, whereas non-activated BAX is predominantly cytosolic but translocates to the MOM upon activation. ${ }^{2} \mathrm{BAX}$ and BAK activation are triggered by binding of $\mathrm{BH}$-only proteins such as BIM or PUMA, following their upregulation by DNA-damaging signals (ultraviolet (UV) light, etoposide) or endoplasmic reticulum (ER) stress. BAX and BAK are also activated by BID after it is cleaved during cytotoxic lymphocyte targeted cell death initiated by human granzyme B (hGrzB). ${ }^{3-7}$ BH3-only proteins also indirectly enhance BAK and BAX function by binding to antiapoptotic Bcl-2 family proteins BCL2, BCLXL, BCLW or MCL1 and so prevent their sequestration of activated $B A X$ and $B A K^{8}$

A series of conformational changes during $B A X$ and BAK activation have recently been identified. Binding of $\mathrm{BH} 3-$ only proteins to a hydrophobic groove on the surface of the two proteins $^{9-12}$ results in exposure of both its $\mathrm{N}$-termini and latch domains. The activated proteins then form symmetric homodimers in which a free BH3-domain binds to the hydrophobic surface groove of another activated monomer. ${ }^{9}$ Dimers then associate into high-order oligomers to form pores and induce MOM permeabilization (MOMP). ${ }^{9}$ Activation and translocation of BAX also requires earlier binding of a $\mathrm{BH}$ only protein to the rear pocket to release the transmembrane domain from the hydrophobic groove. ${ }^{11,13} \mathrm{MOMP}$ results in release of cytochrome $c$, SMAC/Diablo and Omi/HtrA2 to irreversibly activate a cascade of activated caspases. ${ }^{14}$

In one critical pathway to mitochondrial-directed cell death, BID is processed either by caspase-3 at Asp60 or by the proapoptotic serine protease hGrzB at Asp75. ${ }^{15,16}$ hGrzB is delivered from granules of cytotoxic lymphocytes through perforin (Pfn) pores that form in the target cell plasma membrane following conjugate formation between a killer cell and its target. ${ }^{17,18}$ Other caspases that also cleave BID include caspase-2 (upon ER stress induction) and caspase-8 or -10 upon extrinsically mediated death receptor ligation..$^{5,19}$ Once the caspase cascade is activated following MOMP, the cell undergoes irreversible DNA damage, nuclear fragmentation, phosphatidylserine exposure and, ultimately, either phagocytosis or plasma membrane rupture. ${ }^{20}$

\footnotetext{
${ }^{1}$ Cancer Immunology Program, Peter MacCallum Cancer Centre, East Melbourne 3002, Australia; ${ }^{2}$ Sir Peter MacCallum Department of Oncology, The University of Melbourne, Parkville 3052, Australia; ${ }^{3}$ School of Clinical Sciences, Monash University, Clayton 3168, Australia; ${ }^{4}$ The Walter and Eliza Hall Institute of Medical Research, Parkville 3052, Australia; ${ }^{5}$ Department of Medical Biology, University of Melbourne, Parkville 3052, Australia; ${ }^{6}$ Victorian Centre for Functional Genomics, Peter MacCallum Cancer Centre, East Melbourne 3002, Australia; ${ }^{7}$ Department of Biochemistry and Molecular Biology, School of Biomedical Sciences, Monash University, Clayton 3168, Australia and ${ }^{8}$ Cancer Therapeutics Program, Peter MacCallum Cancer Centre, East Melbourne 3002, Australia

*Corresponding author: RW Johnstone or JA Trapani, Cancer Cell Death Laboratory, Cancer Immunology Program, Peter MacCallum Cancer Centre, St Andrew's Place, Locked Bag 1, A'Beckett Street, East Melbourne 3002, Australia. Tel: +61396563727 or +61 39656 1516; Fax: +61 396561411 or +61396561414; E-mail: ricky.johnstone@ petermac.org or joe.trapani@petermac.org

${ }^{9}$ These authors contributed equally to this work.

Abbreviations: MOM, mitochondrial outer membrane; UV, ultraviolet; ER, endoplasmic reticulum; hGrzB, human granzyme B; MOMP, mitochondrial outer membrane permeabilization; Pfn, perforin; PCAF, p300/CBP-associated factor; ADA3, alteration/deficiency in activation 3; PACS, phosphofurin acidic cluster sorting protein; TGN, trans-Golgi network; HAT, histone acetyltransferase; ChIP, chromatin immunoprecipitation; AB, Alamar blue; QVD, Q-VD-OPh; STS, staurosporine; TRAIL, TNF-related apoptosis-inducing ligand

Received 27.11.15; revised 08.8.16; accepted 09.8.16; Edited by L Scorrano; published online 06.1.2017
} 
We recently reported that the mitochondrial pathway of apoptosis is regulated by $\mathrm{p} 300 / \mathrm{CBP}$-associated factor (PCAF) and human alteration/deficiency in activation 3 (ADA3), components of the epigenetic-modifying complexes ATAC and
SAGA. ${ }^{14}$ Moreover, reduced PCAF or ADA3 expression markedly reduces a cell's sensitivity to hGrzB by disrupting BID trafficking and reducing its availability for cleavage by hGrzB. ${ }^{14}$ In turn, we traced cell protection to the decreased

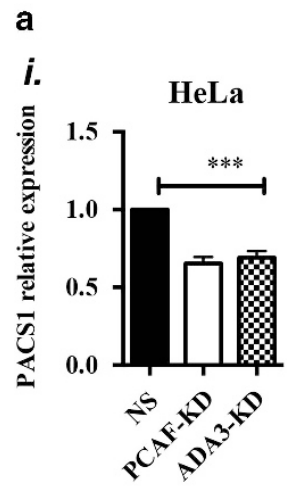

c HeLa

i.

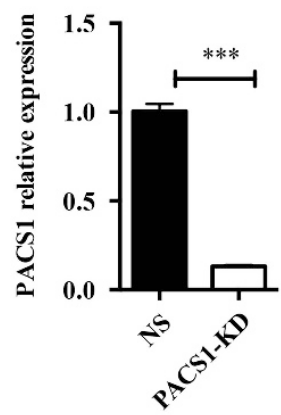

e

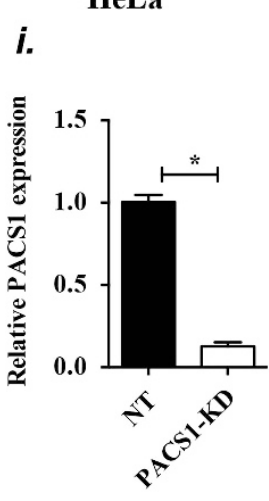

ii. HCT116

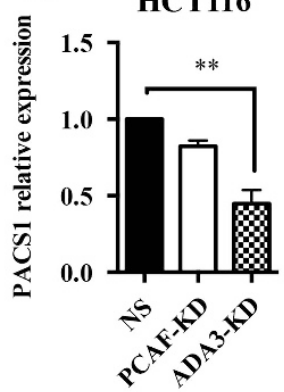

b

HeLa

i.

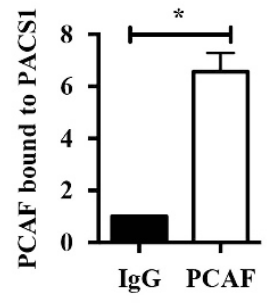

ii.

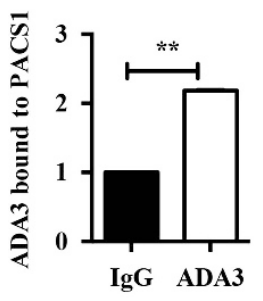

d

HeLa
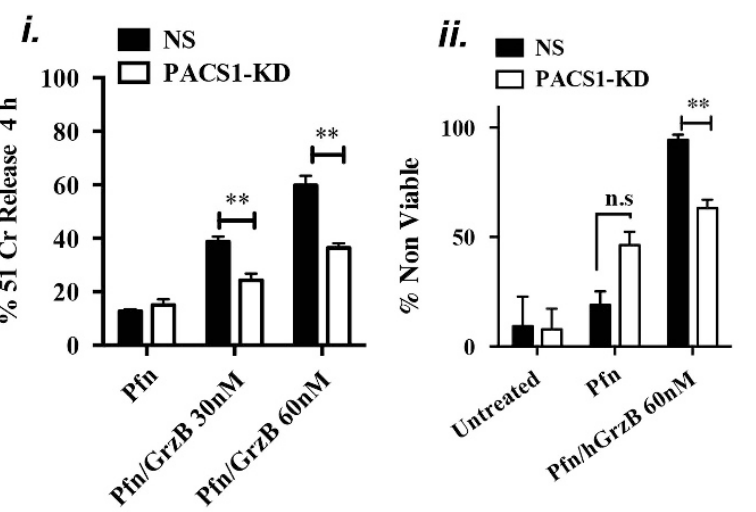

f

HeLa
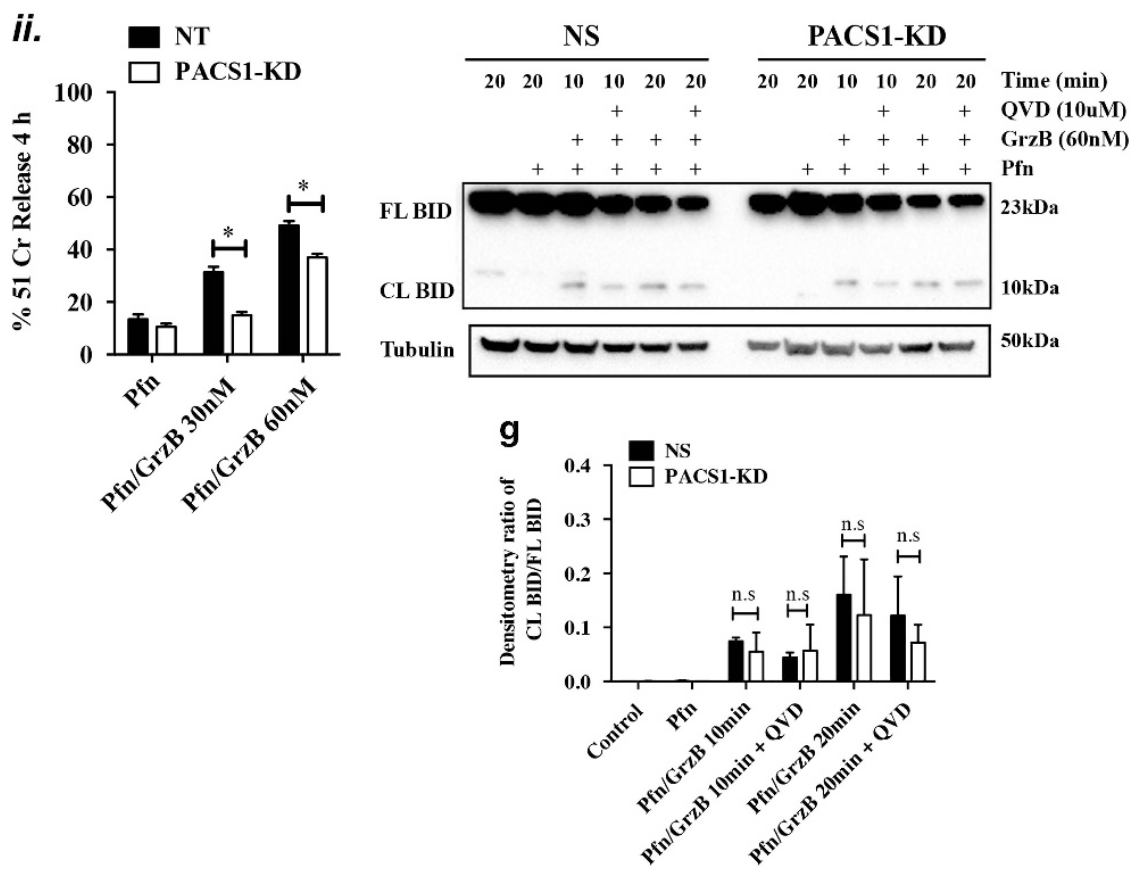
expression of phosphofurin acidic cluster sorting protein 2 (PACS2), a member of the PACS protein family known to regulate protein sorting and trafficking between subcellular secretory compartments. ${ }^{21}$ We now report that PCAF and ADA3 also transcriptionally regulate the related gene PACS1, whose protein product is reported to control protein traffic between the trans-Golgi network (TGN) and the endosomal compartment. Reduced PACS1 expression protected cells from several stimuli that induce death through the mitochondrial pathway, but unlike cells lacking PACS2, BID processing was normal in response to hGrzB. We demonstrate that cell protection following depletion of PACS1 occurs owing to perturbation of BAK and BAX oligomerization that, in turn, diminished MOMP. These studies demonstrate a new and unsuspected role for PACS1 in regulating the intrinsic cell death signaling pathway and highlight PCAF and ADA3 as critical and multifunctional epigenetic regulators of MOMP.

\section{Results}

Reduced PACS1 protects cells from stimuli that activate the intrinsic cell death pathway. PCAF and ADA3 are essential components of multimeric protein complexes that regulate transcription: PCAF is a acetyltransferase (histone acetyltransferase (HAT)) while ADA3 stabilizes the HAT complexes SAGA and ATAC. ${ }^{22}$ We recently showed that PCAF and ADA3 regulate the intrinsic cell death pathway through epigenetic regulation of PACS2, which in turn controls the subcellular trafficking of proapoptotic BID, the preferred target and substrate of hGrzB. ${ }^{14,23}$ These findings led us to assess whether PCAF or ADA3 also control the expression of the related gene PACS1, whose encoded product is thought to regulate protein trafficking from the Golgi to the endosomal compartment. ${ }^{21}$ Using targeted lentivirus shRNA, we found that depleting either PCAF or ADA3 in HeLa cells, or ADA3 in HCT-116 cells, significantly reduced PACS1 mRNA levels (Figure 1a). Chromatin immunoprecipitation (ChIP) assays performed with HeLa cells demonstrated significant enrichment of PCAF and ADA3 at the PACS1 promoter indicating that these proteins directly control the transcription of PACS1 (Figure 1b). Consistent with our previous report, ${ }^{21}$ PCAF and ADA3 also bound specifically to the promoter region of PACS2 (Supplementary Figure S1A).

We previously reported that loss of PCAF or ADA3 protects cells from $\mathrm{Pfn} / \mathrm{hGrzB}$ via PACS2 downregulation that leads to reduced cleavage of BID by hGrzB. ${ }^{14}$ To determine whether PACS1 regulates the intrinsic cell death pathway by the same mechanism, we targeted PACS1 for knockdown by lentivirusmediated shRNA. Significant reduction in the expression of both PACS1 mRNA and protein were demonstrated in comparison to a control 'non-silencing' construct (Figure 1c and Supplementary Figure S1B). There was no significant change in PACS2 mRNA expression following PACS1 knockdown (data not shown). Depletion of PACS1 in HeLa cells exposed to lethal concentrations of hGrzB delivered to their cytosol with an otherwise innocuous concentration of Pfn resulted in increased cell survival in both short-term $(4 \mathrm{~h})$ ${ }^{51} \mathrm{Cr}$ release and longer-term $(24 \mathrm{~h})$ Alamar blue $(A B)$ exclusion assays (Figure 1d). Similar results were observed with HeLa cells in which PACS1 was specifically reduced by transfection with alternative shRNA constructs (data not shown) or a cognate siRNA pool, rather than shRNA (Figure 1e). To address whether, as with PACS2 depletion, the protection endowed by depletion of PACS1 also results from reduced processing of BID by hGrzB, we examined BID cleavage by immunoblot analysis following exposure of cells to $\mathrm{Pfn} / \mathrm{hGrzB}$. To enable discrimination of BID cleavage mediated directly by GrzB or subsequently by activated caspases, we utilized the broad-spectrum caspase inhibitor Q-VD-OPh (QVD) (Figure 1f). Careful densitometry of the signals for the unprocessed and truncated forms of BID from three independent experiments showed the ratio of tBID $(C L)$ to unprocessed (FL) Bid was not significantly changed at either time point or in the presence or absence of QVD (Figure 1g). We concluded that BID processing was unaltered in HeLa cells in which PACS1 levels were reduced (PACS1-KD), both in the presence or absence of QVD. This suggested that, in contrast to PACS2-mediated protection from apoptosis mediated by $\mathrm{Pfn} / \mathrm{hGrzB}$, the protection endowed by reduced PACS1 expression occurs through a different mechanism and maps downstream of BID processing.

Within 2-5 min of accessing the target cell cytosol through Pfn pores, the serine protease hGrzB efficiently cleaves BID

\footnotetext{
Figure 1 Transcriptional regulators PCAF or ADA3 control PACS1 expression, and depletion of PACS1 protects against perforin/hGrzB-induced apoptosis.(a) PCAF or ADA3 knockdown (KD) by shRNA significantly downregulates PACS1 expression. Relative PACS1 expression was determined by qPCR in (i) HeLa and (ii) HCT-116 cells that had shRNAinduced KD of PCAF or ADA3 in comparison to shRNA-transduced non-silencing (NS) cells. (b) PCAF and ADA3 are enriched at the PACS1 promoter. Soluble chromatin from HeLa cells was immunopurified with (i) PCAF or (ii) ADA3 antibodies and analysis by qPCR detected enrichment for PCAF or ADA3 at the PACS1 promoter. An IgG control antibody was used for enrichment comparison. (c) PACS1 is depleted in HeLa transduced with shRNA targeting PACS1. HeLa were transduced with shRNA targeted to PACS1 or NS for stable knockdown and (i) relative expression of PACS1 by qPCR was examined and (ii) immunoblot analysis of PACS1 expression was examined. (d) Reduced stable PACS1 expression in HeLa significantly protects cells from perforin/hGrzB-induced cell death compared with NS control. HeLa cells expressing shRNA for NS or PACS1 were treated with sublytic perforin or perforin/ $h \mathrm{GrzB}$ at the indicated concentrations and analyzed for viability by (i) ${ }^{51} \mathrm{Cr}$, 4-h release assay or (ii) 24-h survival by AB assay. (e) Transient PACS1-KD in HeLa endows protection from perforin/hGrzB-induced death at a level comparative to stable PACS1-KD. HeLa cells were transfected with siRNA for non-targeting (NT) or PACS1 and (i) $48 \mathrm{~h}$ following transfection, relative expression of PACS1 was examined by qPCR. (ii) NT or PACS1-KD cells were treated with sublytic perforin or perforin/hGrzB at the indicated concentrations and ${ }^{51} \mathrm{Cr}$, 4-h release assay was performed to examine viability. (f) Perforin/hGrzB-mediated BID cleavage in HeLa with PACS1-KD or NS. HeLa cells were treated with perforin/hGrzB (60 nM) in the absence or presence of the pan-caspase inhibitor QVD $(10 \mu \mathrm{M})$. Cell lysates for the various conditions shown were analyzed for full length (FL) or cleaved (CL) BID by immunoblot. The immunoblot shown is representative of three independent experiments. (g) Densitometric analysis shows no significant quantitative difference in Bid cleavage in PACS1-KD or NS HeLa cells. The histogram shows the calculated mean ratio of the densitometric signals for CL/FL BID, pooled from three independent experiments $(n=3)$, one of which was the experiment shown in panel (f). Densitometry was quantified using the Image Lab software (Bio-Rad Laboratories). Statistical analyses performed are $t$-test or one-way ANOVA with Bonferroni test comparing NS to PACS1-KD. NS, non significant, ${ }^{*} P<0.05,{ }^{* *} P<0.01$ and ${ }^{* * *} P<0.0001$
} 
and so preferentially activates the mitochondrial cell death pathway, whereas mouse GrzB's subtly different substrate preference causes cell death through procaspase processing and direct caspase activation. ${ }^{15,24-26}$ To determine whether regulation of the mitochondrial pathway by PACS1 is limited to hGrzB or affects other proapoptotic stimuli operating through the same pathway, we exposed HeLa or HCT-116 cells to UV, the topoisomerase II inhibitor etoposide or the broad-spectrum kinase inhibitor staurosporine (STS). The mechanism of cell death of STS remains elusive but was recently shown to involve both canonical mitochondrial apoptosis through BCL2 sequestration and MOMP and a novel, more delayed cell death pathway triggered through BCL-2-independent and apoptosome-independent activation of caspase-9, albeit shown in vitro using high STS concentrations $(\sim 2.5 \mu \mathrm{M}))^{27}$ Etoposide enhances the expression of proapoptotic protein PUMA resulting in BAK/BAX activation. ${ }^{28} \mathrm{UV}$ radiation induces the DNA-damage response activating proapoptotic BCL-2 family of proteins in p53-dependent and -independent mechanisms; it also enhances oxidative stress and cytochrome $c$ release from the mitochondria. ${ }^{29,30}$

Analysis of cell viability by early ( $4 \mathrm{~h}$ ) Annexin V-positivity or late (24 h) trypan blue uptake showed PACS1-KD HeLa cells to be strongly refractory to STS treatment in comparison to control NS cells (Figures 2a (i and ii)). Consistent with their enhanced survival, the PACS1-KD cells showed negligible cleavage of PARP or procaspase-3 processing in comparison to control cells (Figure 2aiii). Treatment with etoposide or UV produced very similar results (Figures $2 b$ and $c$ ). By contrast, HeLa or HCT-116 cells with downregulated PACS1 remained sensitive to cell death mediated through ligation of cell surface receptors for TNF-related apoptosis-inducing ligand (TRAIL), which activates the extrinsic cell death pathway (Supplementary Figure S2A). This indicated that PACS1 primarily regulates the intrinsic (mitochondrial) cell death pathway, the predominant pathway triggered by hGrzB, STS, etoposide and UV radiation. An additional incidental finding from these experiments was that the levels of expression of procaspase-3 and full-length PARP were mildly but consistently increased in PACS1-KD cells. We will follow up this observation in the future studies, but it was notable that PACS1-KD cells became refractory to various apoptotic stimuli despite the apparent increased levels of both a powerful executioner caspase and one of its key targets.
How does PACS1 regulate the intrinsic apoptotic pathway? Following cleavage, truncated (t) BID induces MOMP via activation of BAX and BAK. To test the proposition that PACS1 depletion protects from MOMP, we measured mitochondrial cytochrome $c$ in cells exposed to various death stimuli, by permeabilizing the cell membrane and staining the cells with antibody to cytochrome $c$. Treatment with Pfn/ hGrzB, UV or STS caused around $50 \%$ of NS HeLa cells to undergo mitochondrial cytochrome $c$ release (Figures $3 a-c$ ). In contrast, very few PACS1-KD cells had lost mitochondrial cytochrome $c$ (Figures $3 a-c)$. As protection against cell death might also have resulted from changed expression of proapoptotic (BAK, BAX, BID) or antiapoptotic (MCL1, BCLX, BCL2) proteins, we also assessed the expression levels in PACS1-depleted cells (Supplementary Figure S2B). However, there was no significant alteration in the levels of BAK, $B A X, B I D, M C L 1, B C L X$ or BCL2. The signal for BAX appeared to be enhanced, but careful quantitation of band density of Bax and the tubulin loading control lanes demonstrated no significant increase (data not shown). It was also important to ensure that no other changes in mitochondrial or cellular integrity were introduced by PACS1 depletion. We found that PACS1-KD cells retained the ability to accumulate the mitochondrial membrane dye TMRE, indicating they were able to maintain their mitochondrial membrane potential (Supplementary Figure S2C). PACS1KD and -NS cells were also stained with mitochondrial markers Mito Tracker and cytochrome $c$ and the endosomal markers EEA1 and PDI. No differences in morphology or in the distribution of any of the stains were noted (Supplementary Figure S3).

To further investigate how depletion of PACS1 protects against cell death, we assessed BAK activation using a FACSbased method that detects the exposed $\mathrm{N}$-terminal $\mathrm{BH} 4$ domain in activated BAK. ${ }^{31}$ The G317-2 antibody detected activated BAK in the majority of both control and PACS1-KD HeLa cells following exposure to Pfn/hGrzB (Figures 4a (i-iii)), suggesting that PACS1 acts downstream of BAK activation. BAX activation was also examined with an antibody (6A7) that specifically detects the exposed $\mathrm{N}$-terminus of activated $B A X{ }^{32}$ As expected, most of the control cells treated with $\mathrm{Pfn} / \mathrm{hGrzB}$ contained activated BAX (Figure $4 \mathrm{bi}$ ) and was also the case for PACS1-KD cells (Figure 4bii). We conclude that PACS1 acts downstream of BAK and BAX activation.

\footnotetext{
Figure 2 Depletion of PACS1 in HeLa and HCT-116 cells protects against a variety of apoptotic stimuli. (a) PACS1-KD HeLa are significantly protected from cell death induced by the broad spectrum protein kinase inhibitor STS. Sixteen hours following STS treatment at the indicated concentrations, PACS1-KD or -NS HeLa cells were assessed for viability by (i) Annexin V (AnnV) and 7AAD staining and FACS or (ii) trypan blue staining. The bar charts show the percentage of positively stained (non-viable) cells. (iii) Following 3- and 6-h STS treatment, cells were analyzed by immunoblot for full length (FL) and cleaved (CL) caspase-3 (CSP3), FL or CL PARP compared with a total protein Tubulin immunoblot. (b) PACS1-KD significantly protects cells from the topoisomerase Il inhibitor etoposide. Sixteen hours following etoposide exposure, cell viability was assessed by (i) staining with AnnV and 7AAD followed by FACS or (ii) trypan blue staining. The bar charts show the percentage of positively stained non-viable cells. (iii) Following 3- or 6-h etoposide treatment, lysates were analyzed by immunoblot for FL CSP3 and FL or CL PARP compared with a Tubulin loading control immunoblot. (c) Exposure of NS HeLa or HCT-116 cells to UV radiation induces apoptosis that is not observed in PACS1-KD cells. Cell viability was assessed $16 \mathrm{~h}$ following UV light exposure at the indicated energy densities $\left(\mathrm{J} / \mathrm{cm}^{2}\right)$ by staining with AnnV and 7AAD followed by FACS and a representative bar graph shows the percentage of positive stained non-viable cells for (i) HeLa NS compared with PACS1-KD cells and (ii) HCT-116 NS cells compared with PACS1-KD cells. (iii) Three hours following UV light exposure at the indicated energy densities (J/cm²), HeLa cells with PACS1-KD had reduced apoptotic protein degradation in comparison to NS cells when analyzed by immunoblot for FL and CL CSP3 and FL or CL PARP. A total Tubulin immunoblot was used for loading control. Error bars represent S.E.M, $n=3$. Statistical analyses performed are one-way ANOVA with Bonferroni test comparing NS to PACS1-KD. ${ }^{*} P<0.05$ and ${ }^{* *} P<0.01$. Immunoblots are a representation of three independent experiments
} 
We next examined oligomerization of BAK and of BAX, as oligomerization of one of these proteins is necessary for MOMP. We first assessed BAK oligomerization by inducing disulfide bond formation following addition of the redox catalyst copper(II) (1,10-phenanthroline) $)_{3}$ (CuPhe). Loss of the intramolecular crosslinked form $(\mathrm{Mx})$ following treatment with $\mathrm{Pfn} / \mathrm{hGrzB}$ confirmed BAK activation in both NS and PACS1-KD HeLa cells (Figure 4c, lanes 3 and 5). In addition, BAK could be linked to $2 X$ complexes in NS cells, indicating BAK conversion to oligomers (Figure 4c, lane 3), as expected. However, in PACS1-KD cells treated with Pfn/hGrzB, far fewer $2 \mathrm{X}$ complexes were evident, suggesting failure of activated

a

HeLa

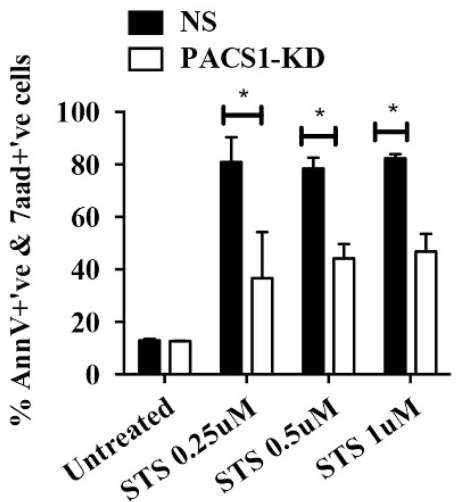

b

i.

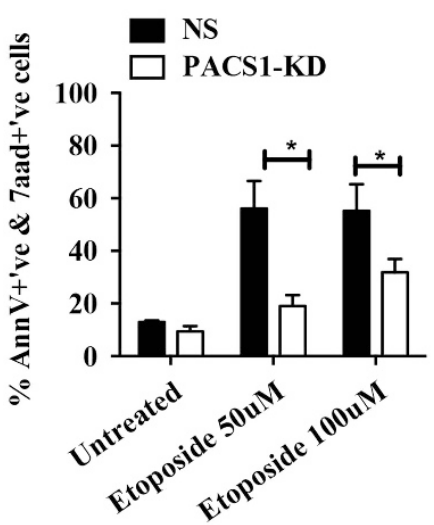

i. HeLa

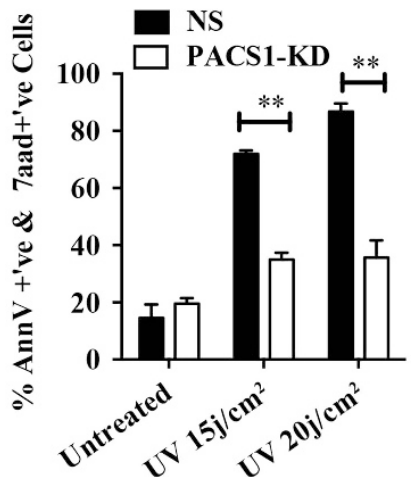

ii.

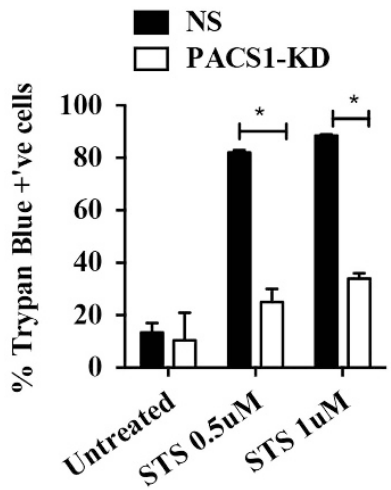

ii.

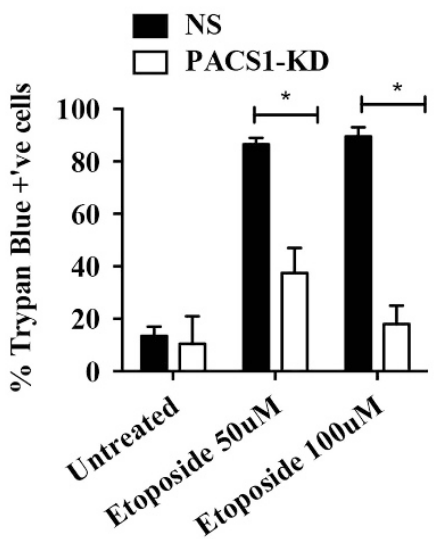

ii. HCT116

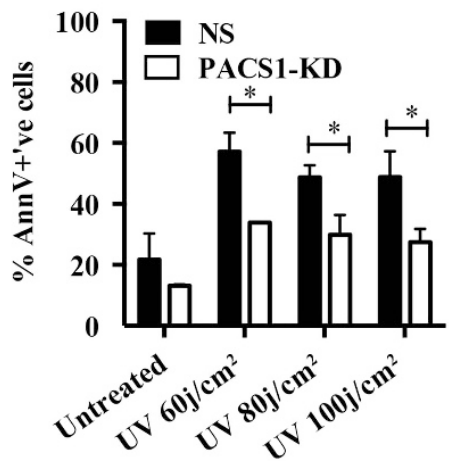

iii.
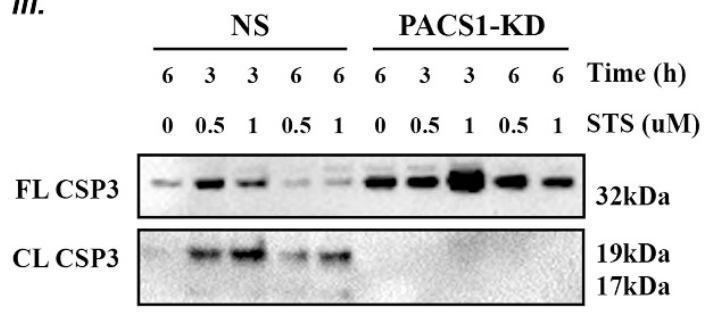

FL PARP $-\cdots-\cdots--\infty-\infty 116 \mathrm{kDa}$

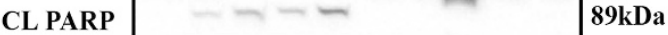

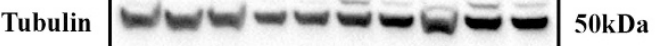

iii.
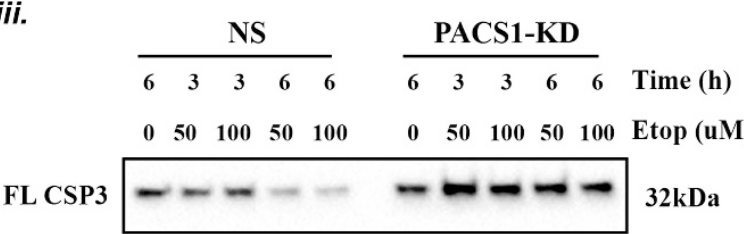

FL PARP

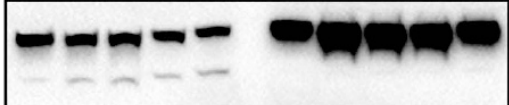

$116 \mathrm{kDa}$

CL PARP

Tubulin

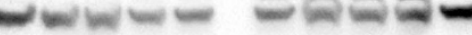
$89 \mathrm{kDa}$

$50 \mathrm{kDa}$

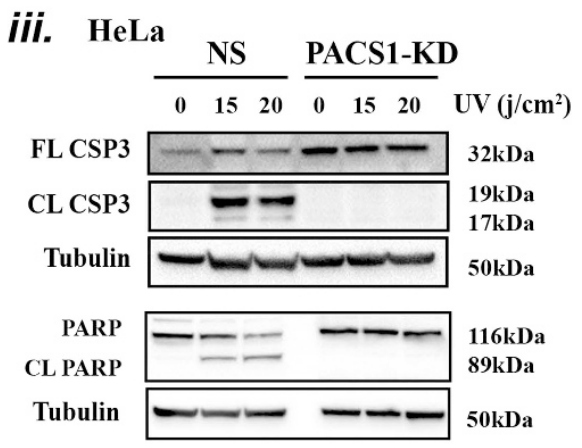


BAK to oligomerize (Figure 4c, lane 5). BAK and BAX activation and oligomerization were also assessed by Blue Native-PAGE (BN-PAGE), as performed previously. ${ }^{2}$ As expected in control cells, Pfn/hGrzB treatment induced formation of BAK homodimers (Figure 4d, left) and a ladder of BAX complexes (Figure 4d, right). However, in PACS1depleted cells, the same treatment caused unusual complexes of BAK and BAX to form. Most of the BAK protein formed a complex around twice the size of BAK dimers. Similarly, most of BAX was present in a complex around twice the size of BAX dimers, instead of forming a ladder. The unusual complexes were also generated when permeabilized PACS1-KD cells were incubated with recombinant $\mathrm{HBID}$, with the complexes still found in the membrane fraction (Figure $4 \mathrm{e}$ ). This perturbation of complex formation suggests that, in the absence of PACS1, activated BAK and BAX proteins are unable to form oligomers capable of pore formation and cytochrome $c$ release. The nature of these complexes and whether proteins other than BAK and BAX are present are topics for further investigation.

\section{Discussion}

We previously performed a functional screen to identify genes that, when silenced, bestow a survival advantage on cells exposed to hGrzB, which activates the mitochondrial cell death signaling pathway. We initially found that PCAF and ADA3 are epigenetic regulators of PACS2 and that ablation of PACS2 expression reduced the capacity of hGrzB to process proapoptotic BID. ${ }^{21}$ Here we show for the first time that PCAF or ADA3 also regulate the expression of the related protein PACS1 and that PACS1 depletion also protects cells against diverse stimuli that activate the mitochondrial pathway. This effect occurred without any discernible disruption of basal mitochondrial function or altered mitochondrial morphology in PACS1-KD cells (Figures 3 and 4; Supplementary Figures S2C and S3). Interestingly, our findings in HeLa (cervical cancer) and HCT-116 (colon cancer) cells contrast with a previous study in which PACS1 depletion in A7 melanoma cells had no influence on apoptosis in response to STS, ${ }^{23}$ a topic for further study.

The mechanism by which PACS1 depletion impedes MOMP maps downstream of BID processing by hGrzB. We found that PACS1-KD did not hinder BAK or BAX activation, suggesting tBID can still bind and activate BAK and BAX. Rather, independent lines of evidence suggested oligomerization of BAK and BAX becomes perturbed in the absence of PACS1. During apoptosis, activated BAK and BAX initially form symmetric $\mathrm{BH} 3$ :groove dimers that then associate to the higher-order oligomers necessary for pore formation and MOMP. ${ }^{11,33,34}$ Whether the complexes observed in PACS1$\mathrm{KD}$ cells on BN-PAGE comprise BH3:groove dimers and whether proteins other than BAK and BAX are present in the complexes remains to be determined. Overall, our work has shown that PACS1 and PACS2 are both agonists in the mitochondrial pathway to cell death but exert their effect by different means; the expression of both is also dependent on PCAF and ADA3.

PACS1 functions specifically in the TGN/endosomal system where it sorts, exports and recovers soluble and membrane- associated proteins of the secretory pathway. ${ }^{21}$ Thus reducing PACS1 expression may cause BAX and BAK to be mislocalized, although this was not evident when cells were fractionated into cytosol and membrane fractions (Figures 4d and e). In several experiments, reducing PACS1 appeared to increase the constitutive levels of full-length caspase-3 and PARP (Figure 2). These findings require further examination to test whether PACS1 may regulate the trafficking, localization and/or turnover of these and perhaps other proteins integral to apoptosis. PACS1 is known to be important for the correct localization of the endoprotease furin, the cation independent mannose-6-phosphate receptor and the SNARE protein VAMP $4,{ }^{21,35}$ and inaccurate localization adversely affects the function of these proteins. ${ }^{21,35}$

PACS1 has been linked to a number of disease settings. It interacts with the HIV-1 protein Nef to induce internalization of $\mathrm{MHC}-\mathrm{I}$, reducing immune recognition of infected cells; it is required for productive infection with human cytomegalovirus, as it is permissive for trafficking the viral envelope glycoprotein $B$ through the TGN; PACS1 is involved in defective trafficking of the amyloid precursor protein to the TGN that ultimately enhances brain plaque formation in Alzheimer's disease; finally, point mutations mapping to the same PACS1 domain were found to underpin three previously unlinked forms of human intellectual disability and growth retardation. ${ }^{36-39}$ PACS1 may also have a role in tumorigenesis. PACS1 maps to chromosome 11q13, which can be deleted in human cervical cancer ${ }^{40}$ and is also implicated in the pathogenesis of some breast, head and neck, endocrine cancers and neuroblastoma. ${ }^{40}$ Variations in PACS1 gene copy number have also been noted in hepatocellular cancer. ${ }^{41}$ Likewise, defective expression of ADA3 or PCAF has also been implicated in a number of malignancies, including gastric, breast and ovarian. ${ }^{42-44}$ While this is perhaps unsurprising given their importance in regulating genes and proteins that regulate the cell cycle, the current study also suggests that affected cells may be less susceptible to death signaled through the mitochondrial pathway, owing to loss of the permissive effects of PACS1 and PACS2.

Given the importance of PACS1 in protein trafficking and disease, understanding its function is of high significance. This is all the more so, given the recent advent of pharmaceutical agents that negatively regulate PCAF, including a PCAFbromodomain inhibitor to inhibit HIV-1 replication. ${ }^{7,45}$ Defining precisely how PACS1 influences BAK or BAX oligomerization may provide the means by which to re-sensitize certain cancer cells to death stimuli that operate through the intrinsic pathway.

\footnotetext{
Material and Methods

Cell culture and reagents. Human HeLa (cervical carcinoma) cells and HCT-116 (colon carcinoma) cells were maintained as described. ${ }^{14}$ For HeLa nonsilencing (NS), ADA3-KD, PCAF-KD and PACS1-KD cells, pGIPZ vectors containing shRNAs targeting NS, ADA3, PCAF or PACS1 were obtained from the Victorian Centre for Functional Genomics (GE Dharmacon RNAi Technologies, Lafayette, CO, USA); sequences and catalog references are as follows: NS, VGH5518; ADA3, 5'-CCAAGATCCAGGAATATGA-3', V2LHS_253631; PCAF, 5'-CAACTAATATACAAC CATA-3', V2LMM_189282; PACS1, 5'-GGCATAAGTTCCCTGATGA-3', V2LHS_ 155295. HeLa or HCT-116 cells expressing shRNA were selected with puromycin ( $2 \mu \mathrm{g} / \mathrm{ml}$, Sigma-Aldrich, St. Louis, MO, USA, P8833) for $48 \mathrm{~h}$ and maintained in culture with $1 \mu \mathrm{g} / \mathrm{ml}$ puromycin for stable cell line continuity. Purified recombinant hGrzB was produced in Pichia pastoris ${ }^{46}$ and recombinant mouse Pfn was
} 

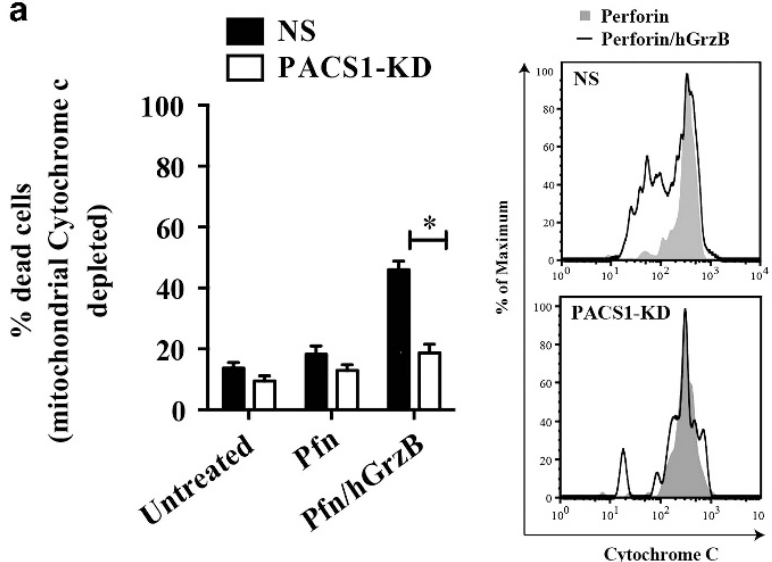

b
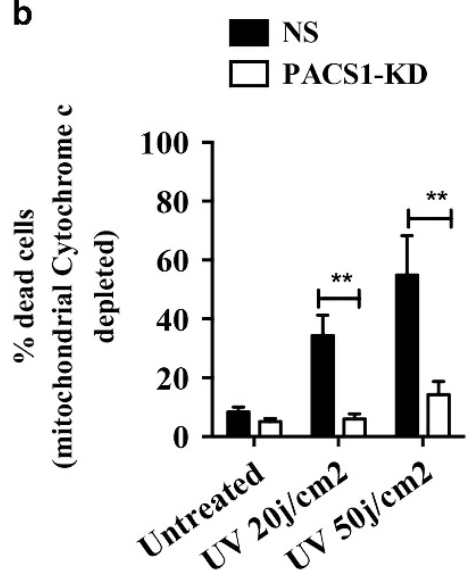

C
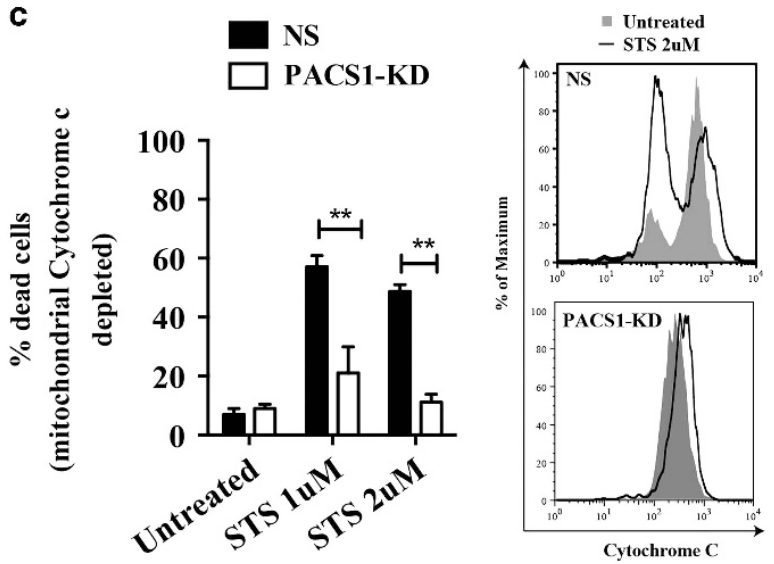

Figure 3 The protection by PACS1-KD is downstream of Bid cleavage, but upstream of cytochrome $c$ release. NS or PACS1-KD HeLa were treated with the indicated apoptotic stimulus and $4 \mathrm{~h}$ following cells were analyzed by staining for cytochrome $c$ and FACS. The bar charts show the percentage of dead cells (mitochondrial cytochrome $c$ depleted) for all the treatment groups. Histograms show FACS overlays of NS or PACS1-KD HeLa cells for the various treatments. A shift to the left indicates cells that have lost undergone mitochondrial cytochrome $c$ release. (a) Bar chart and FACS overlay of HeLa treated with perforin or perforin/hGrzB $(60 \mathrm{nM})$. (b) Bar chart and FACS overlay of HeLa exposed to UV at 20 or $50 \mathrm{~J} / \mathrm{cm}^{2}$. (c) Bar chart and FACS overlays of STS-treated HeLa at 1 or $2 \mu \mathrm{M}$. Error bars represent S.E.M, $n=3$. Statistical analyses performed are one-way ANOVA with Bonferroni test comparing NS to PACS1-KD. ${ }^{*} P<0.05$ and ${ }^{* *} P<0.01$ produced in baculovirus-infected Sf9 or Sf21 cells. ${ }^{47}$ Caspases were blocked with QVD $(10 \mu \mathrm{M}$, Calbiochem, Darmstadt, Germany, 551476). Human TRAlL ligand was from Peprotech, Rocky Hill, NJ, USA, 310-04. Cells were exposed to UV light $\left(15-50 \mathrm{~J} / \mathrm{cm}^{2}\right.$ ) using a Ultraviolet Crosslinker (UVP, Upland, CA, USA, CL1000) or treated with STS (Sigma-Aldrich, S5921) or etoposide (Sigma-Aldrich, E1383) at the indicated times and concentrations.

Transfections and transductions. For lentivirus production, HEK293T cells were transfected with pGIPZ plasmids and LentiX-HT packaging mix (Clonetech, Mountain View, CA, USA, 631247) using the polyethlenimine (PolySciences, Warrington, PA, USA, 23966-2) transfection method. Forty-eight hours after transfection, media containing virus was collected and HeLa or HCT-116 cells were transduced and cultured for $16 \mathrm{~h}$ and the media was refreshed. Successfully transduced cells were selected with puromycin $(2 \mu \mathrm{g} / \mathrm{ml})$ for $48 \mathrm{~h}$. For siRNA transfection of HeLa, we used reverse transfection to transiently transfect HeLa cells with ON-TARGETplus SMARTpool siRNAs (catalog reference: nontargeting (NT) D-001810; PACS1 L-006697-01-0005; GE Dharmacon RNAi Technologies). Briefly, DharmaFECT1 lipid (T-2001) was added to Opti-MEM (ThermoFisher Scientific, Waltham, MA, USA, 51985091) along with siRNA (final concentration of $40 \mathrm{nM}$ ) and complexed for $20 \mathrm{~min}$. HeLa cells prepared in maintenance medium were added to the well after the complexing was complete. The medium was refreshed at $16 \mathrm{~h}$ and the cells were harvested at $24 \mathrm{~h}$.

Immunoblot analysis. For SDS-PAGE, cell lysates were prepared in NP40 lysis buffer and protein quantification was determined by Coomassie-Bradford (ThermoFisher Scientific, 23200). Lysates were separated on 4-12\% NuPage Bis-Tris gradient gels (ThermoFisher Scientific, NP0341), the proteins were transferred to PVDF membranes and probed using antibodies to: PACS1 (Abnova, Taipei, Taiwain, PAB23363); full-length (FL) caspase-3 (BD Transduction Laboratories, Franklin Lakes, NJ, USA, 610322); cleaved (CL) caspase-3 (Cell Signaling, Danvers, MA, USA, 9661); $\mathrm{FL}$ and CL PARP (Cell Signaling, 9532); FL and CL BID (clone no. 2D1, WEH Monoclonal Antibody Facility, Melbourne, Victoria, Australia); BAK (amino acids 23-38, Sigma-Aldrich, B5897); BAX (Santa Cruz, Santa Cruz, CA, USA sc-493); MCL1 (Cell Signaling, 556467); BCLX (Santa Cruz, sc-8392); Tubulin (Sigma-Aldrich, T9026), and BCL2 (BD Biosciences, San Jose, CA, USA, 551051). Secondary antibodies were horseradish peroxidase-conjugated anti-rabbit IgG, anti-mouse IgG and anti-rat IgG (DAKO, Santa Clara, CA, USA, P0448, P0447, P0450). Immunoblot images were processed using a BIORAD GelDoc system (Hercules, CA, USA) and densitometry was performed using the Image Lab software (Bio-Rad Laboratories, CA, USA ).

For BN-PAGE analysis, the PVDF membranes were probed using anti-BAK monoclonal rat IgG (Clone 7D10) ${ }^{48}$ and anti-BAX monoclonal rat IgG (Clone 49F9). ${ }^{11}$ The secondary antibody was horseradish peroxidase-conjugated goat anti-rat IgG (Southern Biotech, Birmingham, AL, USA, 3030-05).

RNA isolation and first-strand cDNA synthesis. Total RNA was isolated using a RNeasy Mini Kit (Qiagen, Hilden, Germany, 74104) according to the manufacturer's instructions. First-strand cDNA synthesis was performed using M-MLV Reverse Transcriptase (Promega, Madison, WI, USA, M1701) according to the manufacturer's instructions. HPRT (forward 5 '-CCTGGCGTCGTGATTAGTGAT $-3^{\prime}$, reverse 5'-AGACGTTCAGTCCTGTCCATAA-3') and PACS1 (forward, 5'-GT GCCTGTGGCAGAAATAAAGA-3', reverse 5' ${ }^{\prime}$-AGGGTAAAGTCAAAATGAA AATGCTT-3') genes were quantified by quantitative PCR (qPCR) using an $A B I$ Prism-7500 (Life Technologies, Grand Island, NY, USA) with 2 pmol of each primer in $20 \mu \mathrm{l} 1 \times$ POWER Sybergreen PCR Mastermix (Life Technologies). Annealing was at $50^{\circ} \mathrm{C}$ for $2 \mathrm{~min}$, denaturing at $95^{\circ} \mathrm{C}$ for $10 \mathrm{~min}$ followed by 40 synthesis cycles at $60^{\circ} \mathrm{C}$ for $1 \mathrm{~min}$.

Chromatin immunoprecipitation. ChIP assays were performed as described ${ }^{49}$ with minor modifications. In brief, cells were fixed with formaldehyde $(1 \%)$ for $10 \mathrm{~min}$, treated with glycine $(0.15 \mathrm{M})$ for $10 \mathrm{~min}$, harvested and pelleted. Cell pellets were resuspended in SDS lysis buffer (1\% SDS, $10 \mathrm{mM}$ EDTA, $50 \mathrm{mM}$ Tris, (pH 8.1)) sonicated to shear chromatin and resuspended in ChIP dilution buffer (0.01\% SDS, 1.1\% Triton X-100, $1.2 \mathrm{mM}$ EDTA, $16.7 \mathrm{mM}$ Tris-HCl, $\mathrm{pH} 8.1$ and $167 \mathrm{mM} \mathrm{NaCl}$ ). Immunoprecipitation was performed by adding the soluble chromatin fraction to $10 \mu \mathrm{g}$ of either of the following antibodies: rabbit anti-PCAF (A301-666A, Bethyl Laboratories, Montgomery, TX, USA), rabbit anti-ADA3 (ab77011, Abcam, Cambridge, UK), or normal rabbit IgG (ab16640, Abcam), along with protein A-Dynabeads (10001D, ThermoFisher Scientific). Inputs and immune complexes were washed and eluted with buffer ( $1 \% \mathrm{SDS}, 0.1 \mathrm{M} \mathrm{NaHCO}_{3}$ ) 
i.

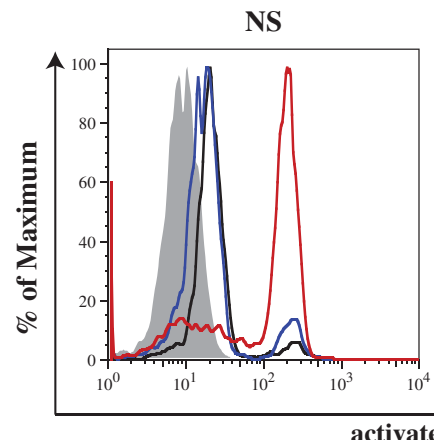

ii.

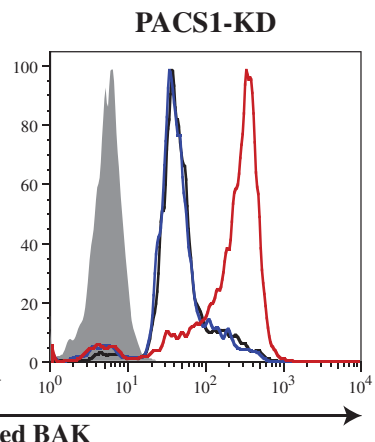

b

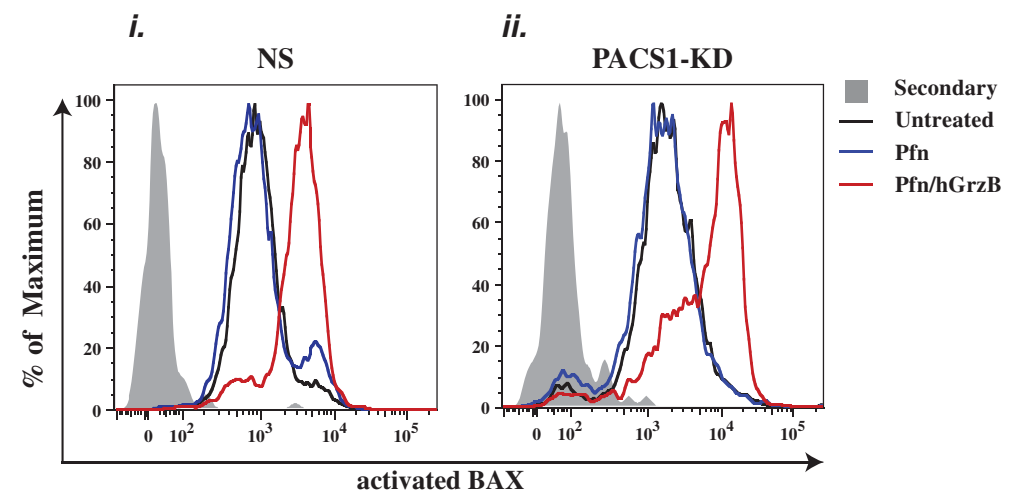

iii.

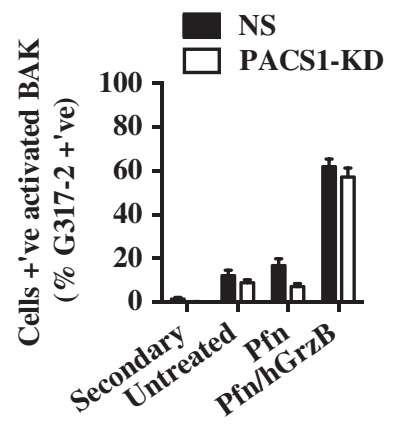

iii.

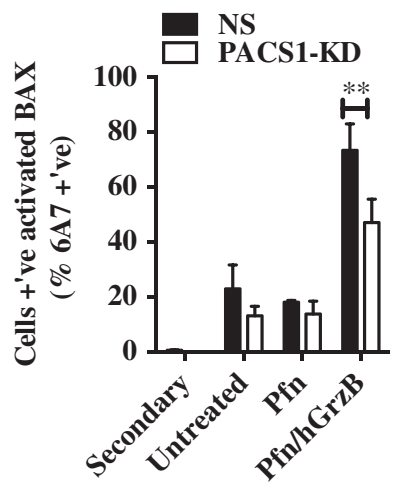

C

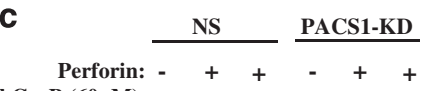

Terforin: -++-++

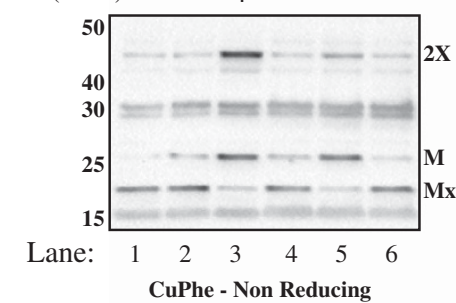

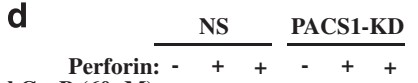

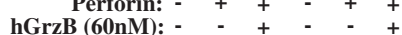

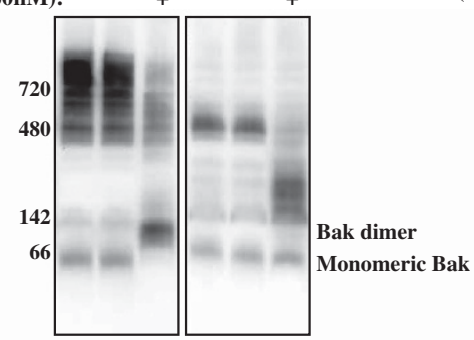

Perforin: - + $+\frac{\text { PACS1-KD }}{-++}$

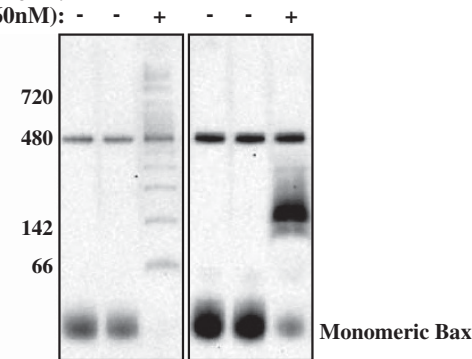

e

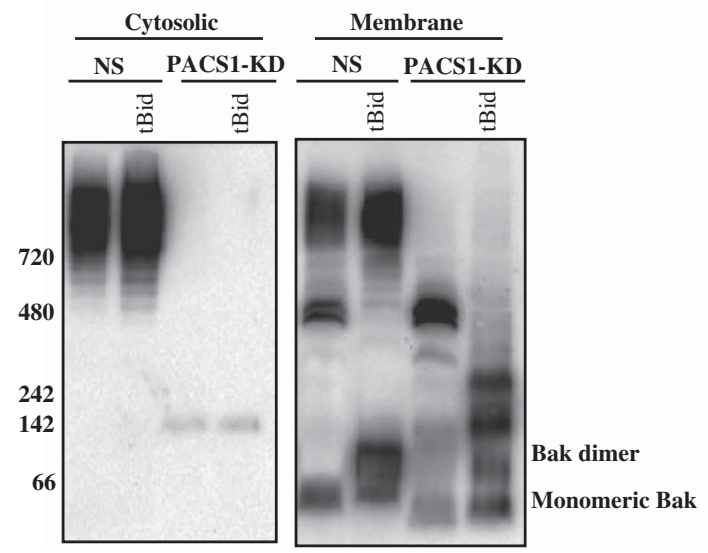

BAK immunoblot
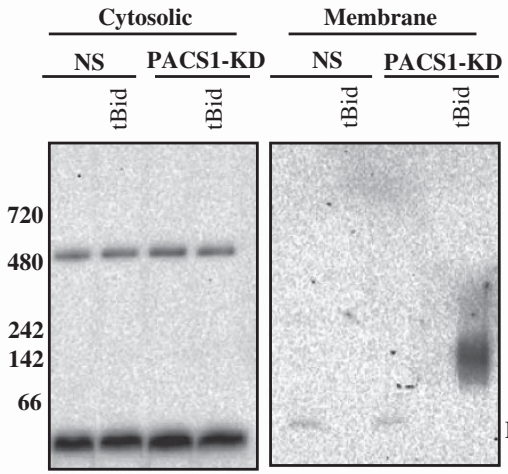

Monomeric Bax

BAX immunoblot 
Figure 4 PACS1 knockdown alters oligomerization of activated BAK and BAX after hGrzB treatment. (a) PACS1 knockdown does not block activation of BAK. NS or PACS1KD HeLa were treated with perforin in the absence or presence of $\mathrm{hGrzB}(60 \mathrm{nM})$ for $1 \mathrm{~h}$ and analyzed for BAK N-terminal exposure by FACS. Representative FACS plots for (i) HeLa NS cells treated with Pfn/hGrzB or (ii) HeLa PACS1-KD cells treated with Pfn/hGrzB. (iii) Representative bar chart of FACS G317-2 staining of HeLa NS or PACS1-KD cells treated with Pfn/hGrzB. (b) PACS1 knockdown only partially blocks BAX activation. Cells incubated as in panel (a) were analyzed for BAX N-terminal exposure by FACS. Representative FACS overlay of (i) HeLa NS treated with Pfn/hGrzB or (ii) HeLa PACS1-KD cells treated with Pfn/hGrzB. (iii) Representative bar chart of FACS 6A7 staining of HeLa NS, PACS1-KD cells treated with Pfn/hGrzB compared with HeLa NS cells. (c) PACS1 knockdown decreases detection of linked BAK complexes. Cells incubated as in panel (a) were treated with the oxidant CuPhe to induce disulfide bond formation and analyzed for BAK oligomerization on non-reducing SDS-PAGE. Immunoblot shows loss of intramolecular disulfide linkage $\left(M_{\mathrm{x}}\right)$ and gain of activated BAK monomer (Monomeric) following Pfn/hGrzB treatment of both NS or PACS1-KD HeLa. However, linkage between Bak molecules (2X) is greatly reduced in PACS1-KD HeLa (lane 5) compared with NS HeLa (lane 3), indicating that activated BAK had failed to oligomerize in PACS1-KD HeLa in a way that allows disulfide bonds to form between the cysteine residues C14 and C166. (d) PACS1 knockdown alters BAK and BAX complexes detected by BN-PAGE. Cells incubated as in panel (a) were analyzed for BAK or BAX activation and dimerization by Blue Native PAGE and immunoblot analysis. Error bars represent S.E.M, $n=3$. Statistical analyses performed are one-way ANOVA with Bonferroni test comparing NS to PACS1-KD. ${ }^{*} P<0.01$. Immunoblots are representative of three independent experiments. (e) PACS1 knockdown also alters BAK and BAX complexes generated in response to tBID. NS or PACS1-KD HeLa cells were permeabilized with digitonin and incubated with recombinant tBID prior to separation of cytosolic and membrane fractions and analysis on Blue Native PAGE and immunoblot analysis for (a) BAK or (b) BAX

and then incubated with Proteinase $\mathrm{K}$ for $2 \mathrm{~h}$ at $62^{\circ} \mathrm{C}$ on a thermomixer. DNA was eluted using the MinElute Reaction Clean Up Kit (28204, Qiagen). The PACS1 (forward 5'-CAGGGTGCTGTGTCTTACAGTTTG-3' and reverse 5'-GGGCTTTCTGGGTGAAACC-3') or PACS2 (forward 5'-TCTTGCCA TTGCGGAAGACT-3' and reverse 5'-CCTTAGCCTGGGAGCTTCCT-3') promoters were amplified by $\mathrm{QPCR}$ amplification where $\mathrm{qPCR}$ values were normalized to input DNA and to the rabbit IgG values, and relative fold changes were calculated.

Cytotoxicity assays. In all, $0.5 \times 10^{6}$ cells were treated at $37^{\circ} \mathrm{C}$ with $\mathrm{hGrzB}$ at the specified concentration and a concentration of Pfn pretitrated to produce $<10 \%$ cell lysis. Chromium $\left({ }^{51} \mathrm{Cr}\right)$ and cytochrome $c$ release assays were performed as previously described. ${ }^{50,51}$ For flow cytometry (FACS), cells were washed with PBS containing $0.5 \% \mathrm{FCS}$ and then resuspended in the same solution with 7-AAD-FITC (IM3614, Beckman Coulter, Brea, CA, USA) and fluorescence was detected on a cytofluorograph. $A B$ exclusion was performed according to the manufacturer's instructions (DAL1025, ThermoFisher Scientific). Cells were stained with TMRE (Molecular Probes, Eugene, OR, USA) according to the manufacturer's instructions.

Disulfide bond formation. Membrane fractions from HeLa cells were obtained by digitonin permeabilization and resuspension in crosslinking buffer (20 $\mathrm{mM} \mathrm{HEPES} / \mathrm{KOH}$ (pH 7.5), $100 \mathrm{mM}$ sucrose, $2.5 \mathrm{mM} \mathrm{MgCl}_{2}$, and $50 \mathrm{mM} \mathrm{KCl}$ ) as described. ${ }^{33}$ For disulfide bond formation, membrane fractions were incubated with the redox catalyst CuPhe on ice for $30 \mathrm{~min}$. The CuPhe stock was $30 \mathrm{mM} \mathrm{CuSO}_{4}$ and $100 \mathrm{mM} \mathrm{1,10-phenanthroline} \mathrm{in} \mathrm{4:1} \mathrm{water/ethanol} \mathrm{and} \mathrm{diluted} \mathrm{100-fold} \mathrm{into} \mathrm{the}$ sample. Oxidation was quenched by adding $20 \mathrm{mM}$ EDTA to chelate copper and $20 \mathrm{mM}$ N-ethylmaleimide to block unreacted cysteine residues. Samples were then analyzed by non-reducing SDS-PAGE.

Blue Native-PAGE. BN-PAGE was performed as described ${ }^{31}$ with minor modifications. Briefly, membrane fractions from treated HeLa cells were solubilized in $20 \mathrm{mM}$ Bis-tris, $\mathrm{pH} 7.4,50 \mathrm{mM} \mathrm{NaCl}$ and $10 \%$ glycerol with $1 \%$ digitonin for $30 \mathrm{~min}$ on ice and centrifuged at $13000 \times g$ to pellet detergent-insoluble debris. BNPAGE loading dye (NativePAGE $5 \%$ G-250 additive in $4 \times$ NativePAGE sample buffer (Life Technologies)) was added to each sample supernatant. Electrophoresis was for $2 \mathrm{~h}$ at $150 \mathrm{~V}$ in $1 \times$ NativePAGE running buffer (Life Technologies) and blue cathode buffer ( $1 \times$ running buffer containing $1 \times$ NativePAGE running buffer (Life Technologies)). Blue cathode buffer was replaced with $1 \times$ running buffer after 40 min. Proteins were transferred to PVDF in Tris-glycine buffer containing $20 \%$ methanol and $0.037 \%$ SDS. Prior to immunoblotting, membranes were destained for $10 \mathrm{~min}$ in $30 \%$ ethanol:10\% acetic acid, washed three times for $10 \mathrm{~min}$ in water, then destained further in $100 \%$ methanol for 5 min and washed three times for $10 \mathrm{~min}$ in water.

Detection of BAK or BAX activation by FACS. HeLa-treated cells were permeabilized and analyzed for activation of BAK or BAX as described. ${ }^{31}$ Briefly, samples were centrifuged and washed with FACS buffer (10\% FBS: 90\% (1.2 mM $\mathrm{MgSO}_{4}, 7.4 \mathrm{mM}$ HEPES-NaOH, $0.8 \mathrm{mM} \mathrm{K}_{2} \mathrm{HPO}_{4}, 140 \mathrm{mM} \mathrm{NaCl}$ )) and incubated 60 min on ice with anti-BAK antibody G317-2 (B5897, Sigma-Aldrich) or anti-BAX antibody 6A7 (56467, BD Biosciences) diluted 1:100 in FACS buffer. After incubation, cells were washed with FACS buffer and incubated 60 min on ice with RPE-labeled anti-mouse secondary antibody (A10543, Life Technologies) diluted 1:200 in FACS buffer. The cells were washed with FACS buffer, and data were collected immediately using a CANTOIl flow cytometer (BD) fitted with FACSDiVa software (BD) and subsequently analyzed using FlowJo v. 9.5.2 (FlowJo LLC, Ashland, OR, USA).

Subcellular fractionation. Cells were harvested and permeabilized in buffer (20 mM Hepes ( $\mathrm{pH} 7.5$ ), $100 \mathrm{~mm} \mathrm{KCl}, 2.5 \mathrm{~mm} \mathrm{MgCl} 2$ and $100 \mathrm{~mm}$ sucrose) containing $0.025 \%$ digitonin and supplemented with complete protease inhibitors without EDTA (Roche, Basel, Switzerland). Permeabilization was confirmed by trypan blue uptake, and cytosol and membrane fractions were separated by centrifugation at $13000 \times \mathrm{g}$ for $5 \mathrm{~min}$ prior to SDS-PAGE analysis. Pelleted membrane fractions were resuspended in permeabilization buffer without digitonin and incubated with or without caspase 8-cleaved human BID (tBID, $20 \mathrm{nM}$ ) at $30^{\circ} \mathrm{C}$ for $30 \mathrm{~min}$. Supernatant and membrane fractions were separated by centrifugation at $13000 \times g$ for 5 min prior to BN-PAGE.

Incubation of permeabilized HeLa cells with tBID. HeLa cells were permeabilized with $0.025 \%$ digitonin as above and incubated in the presence of $10 \mathrm{nM}$ DTT with $100 \mathrm{nM}$ recombinant $\mathrm{BBID}$ for $30 \mathrm{~min}$ at $30^{\circ} \mathrm{C}$ as described in Dewson et al..$^{52}$ Following centrifugation at $13000 \times g$ for 5 min, cytosol and membrane fractions were processed for BN-PAGE as above.

Statistical analysis. Results are presented as mean \pm S.E.M. Statistical differences were evaluated by $t$-test or one-way ANOVA with Bonferroni adjustment by the Prism software (GraphPad, La Jolla, CA, USA). A P-value of $<0.05$ was considered significant.

\section{Conflict of Interest}

The authors declare no conflict of interest.

Acknowledgements. This study was supported by Program, Fellowship and Project grant support from the National Health and Medical Research Council (NHMRC) of Australia and the Cancer Council Victoria, Australia. We thank the Australian Cancer Research Foundation for supporting the Victorian Centre for Functional Genomics and the Australian Government's Education Investment Fund Super Science Initiative support of the Australian Phenomics Network.

\section{Author contributions}

DB performed ChIP assays and BAK or BAX activation assays. DB and TN performed transfections and transductions, $\mathrm{QPCR}$, immunoblotting, cytotoxic assays and FACS analysis. ML and SI performed Blue Native PAGE experiments. AEA performed Blue Native PAGE, provided intellectual input and critical comments on the manuscript. RMK provided intellectual input and critical comments on the manuscript. KJS provided lentiviral constructs, siRNAs and technical support for the retroviral screen. PIB made recombinant hGrzB. DB, RWJ and JAT designed the experiments, analyzed data and wrote the manuscript.

1. Trapani JA, Smyth MJ. Functional significance of the perforin/granzyme cell death pathway. Nat Rev Immunol 2002; 2: 735-747. 
2. Ma SB, Nguyen TN, Tan I, Ninnis R, lyer S, Stroud DA et al. Bax targets mitochondria by distinct mechanisms before or during apoptotic cell death: a requirement for VDAC2 or Bak for efficient Bax apoptotic function. Cell Death Differ 2014; 21: 1925-1935.

3. Letai A, Bassik MC, Walensky LD, Sorcinelli MD, Weiler S, Korsmeyer SJ. Distinct BH3 domains either sensitize or activate mitochondrial apoptosis, serving as prototype cancer therapeutics. Cancer Cell 2002; 2: 183-192.

4. Ren D, Tu HC, Kim H, Wang GX, Bean GR, Takeuchi O et al. BID, BIM, and PUMA are essential for activation of the BAX- and BAK-dependent cell death program. Science 2010; 330: 1390-1393.

5. Upton JP, Austgen K, Nishino M, Coakley KM, Hagen A, Han D et al. Caspase-2 cleavage of $\mathrm{BID}$ is a critical apoptotic signal downstream of endoplasmic reticulum stress. Mol Cell Biol 2008; 28: 3943-3951.

6. Westphal D, Kluck RM, Dewson G. Building blocks of the apoptotic pore: how Bax and Bak are activated and oligomerize during apoptosis. Cell Death Differ 2014; 21: 196-205.

7. Wang $Q$, Wang R, Zhang B, Zhang S, Zheng Y, Wang Z. Small organic molecules targeting PCAF bromodomain as potent inhibitors of HIV-1 replication. Med Chem Commun 2013; 4 737-740.

8. Chen L, Willis SN, Wei A, Smith BJ, Fletcher Jl, Hinds MG et al. Differential targeting of prosurvival $\mathrm{Bcl}-2$ proteins by their $\mathrm{BH} 3-$ only ligands allows complementary apoptotic function. Mol Cell 2005; 17: 393-403.

9. Moldoveanu T, Grace CR, Llambi F, Nourse A, Fitzgerald P, Gehring K et al. BID-induced structural changes in BAK promote apoptosis. Nat Struct Mol Biol 2013; 20: 589-597.

10. Dai H, Smith A, Meng XW, Schneider PA, Pang YP, Kaufmann SH. Transient binding of an activator $\mathrm{BH} 3$ domain to the Bak $\mathrm{BH} 3$-binding groove initiates Bak oligomerization. J Cell Bio 2011; 194: 39-48.

11. Czabotar PE, Westphal D, Dewson G, Ma S, Hockings C, Fairlie WD et al. Bax crystal structures reveal how $\mathrm{BH} 3$ domains activate $\mathrm{Bax}$ and nucleate its oligomerization to induce apoptosis. Cell 2013; 152: 519-531.

12. Brouwer JM, Westphal D, Dewson G, Robin AY, Uren RT, Bartolo R et al. Bak core and latch domains separate during activation, and freed core domains form symmetric homodimers. Mol Cell 2014; 55: 938-946.

13. Gavathiotis E, Reyna DE, Bellairs JA, Leshchiner ES, Walensky LD. Direct and selective small-molecule activation of proapoptotic BAX. Nat Chem Biol 2012; 8: 639-645.

14. Brasacchio D, Noori T, House C, Brennan AJ, Simpson KJ, Susanto $O$ et al. A functional genomics screen identifies PCAF and ADA3 as regulators of human granzyme B-mediated apoptosis and Bid cleavage. Cell Death Differ 2014; 21: 748-760.

15. Sutton VR, Wowk ME, Cancilla M, Trapani JA. Caspase activation by granzyme B is indirect, and caspase autoprocessing requires the release of proapoptotic mitochondrial factors. Immunity 2003; 18: 319-329.

16. Sutton VR, Davis JE, Cancilla M, Johnstone RW, Ruefli AA, Sedelies K et al. Initiation of apoptosis by granzyme $\mathrm{B}$ requires direct cleavage of bid, but not direct granzyme B-mediated caspase activation. J Exp Med 2000; 192: 1403-1414.

17. Voskoboinik I, Whisstock JC, Trapani JA. Perforin and granzymes: function, dysfunction and human pathology. Nat Rev Immunol 2015; 15: 388-400.

18. Lopez JA, Susanto O, Jenkins MR, Lukoyanova N, Sutton VR, Law RH et al. Perforin forms transient pores on the target cell plasma membrane to facilitate rapid access of granzymes during killer cell attack. Blood 2013; 121: 2659-2668.

19. Li H, Zhu H, Xu CJ, Yuan J. Cleavage of BID by caspase 8 mediates the mitochondria damage in the Fas pathway of apoptosis. Cell 1998; 94: 491-501.

20. Susanto O, Trapani JA, Brasacchio D. Controversies in granzyme biology. Tissue Antigens 2012; 80: 477-487

21. Wan L, Molloy SS, Thomas L, Liu G, Xiang Y, Rybak SL et al. PACS-1 defines a novel gene family of cytosolic sorting proteins required for trans-Golgi network localization. Cell 1998; 94: 205-216.

22. Spedale G, Timmers HT, Pijnappel WW. ATAC-king the complexity of SAGA during evolution. Genes Dev 2012; 26: 527-541.

23. Simmen T, Aslan JE, Blagoveshchenskaya AD, Thomas L, Wan L, Xiang Y et al. PACS-2 controls endoplasmic reticulum-mitochondria communication and Bid-mediated apoptosis. EMBO J 2005; 24: 717-729.

24. Sutton VR, Vaux DL, Trapani JA. Bcl-2 prevents apoptosis induced by perforin and granzyme B, but not that mediated by whole cytotoxic lymphocytes. J Immunol 1997; 158: $5783-5790$.

25. Kaiserman D, Bird CH, Sun J, Matthews A, Ung K, Whisstock JC et al. The major human and mouse granzymes are structurally and functionally divergent. J Cell Biol 2006; 175: 619-630.

26. Andoniou CE, Sutton VR, Wikstrom ME, Fleming P, Thia KY, Matthews AY et al. A natural genetic variant of granzyme $B$ confers lethality to a common viral infection. PLOS Pathogens 2014; 10: e1004526.

27. Manns J, Daubrawa M, Driessen S, Paasch F, Hoffmann N, Loffler A et al. Triggering of a novel intrinsic apoptosis pathway by the kinase inhibitor staurosporine: activation of caspase9 in the absence of Apaf-1. FASEB J 2011; 25: 3250-3261.
28. Korwek Z, Sewastianik T, Bielak-Zmijewska A, Mosieniak G, Alster O, Moreno-Villanueva M et al. Inhibition of ATM blocks the etoposide-induced DNA damage response and apoptosis of resting human T cells. DNA Repair 2012; 11: 864-873.

29. Ziegler A, Jonason AS, Leffell DJ, Simon JA, Sharma HW, Kimmelman J et al. Sunburn and p53 in the onset of skin cancer. Nature 1994; 372: 773-776.

30. Nys K, Van Laethem A, Michiels C, Rubio N, Piette JG, Garmyn M et al. A p38(MAPK)/HIF-1 pathway initiated by UVB irradiation is required to induce Noxa and apoptosis of human keratinocytes. J Invest Dermatol 2010; 130: 2269-2276.

31. Alsop AE, Fennell SC, Bartolo RC, Tan IK, Dewson G, Kluck RM. Dissociation of Bak alpha1 helix from the core and latch domains is required for apoptosis. Nat Commun 2015; 6: 6841.

32. Steckley D, Karajgikar M, Dale LB, Fuerth B, Swan P, Drummond-Main C et al. Puma is a dominant regulator of oxidative stress induced Bax activation and neuronal apoptosis. J Neurosci 2007; 27: 12989-12999.

33. Dewson G, Kratina T, Sim HW, Puthalakath H, Adams JM, Colman PM et al. To trigger apoptosis, Bak exposes its $\mathrm{BH} 3$ domain and homodimerizes via $\mathrm{BH} 3$ :groove interactions. Mol Cell 2008; 30: 369-380.

34. Dewson G, Ma S, Frederick P, Hockings C, Tan I, Kratina T et al. Bax dimerizes via a symmetric BH3:groove interface during apoptosis. Cell Death Differ 2012; 19: 661-670.

35. Hinners I, Wendler F, Fei $H$, Thomas $L$, Thomas G, Tooze SA. AP-1 recruitment to VAMP4 is modulated by phosphorylation-dependent binding of PACS-1. EMBO Rep 2003; 4: 1182-1189.

36. Burgert T, Schmidt V, Caglayan S, Lin F, Fuchtbauer A, Fuchtbauer EM et al. SORLAdependent and -independent functions for PACS1 in control of amyloidogenic processes. Mol Cell Biol 2013; 33: 4308-4320.

37. Crump CM, Hung $\mathrm{CH}$, Thomas L, Wan L, Thomas G. Role of PACS-1 in trafficking of human cytomegalovirus glycoprotein B and virus production. J Virol 2003; 77: 11105-11113.

38. Dikeakos JD, Thomas L, Kwon G, Elferich J, Shinde U, Thomas G. An interdomain binding site on HIV-1 Nef interacts with PACS-1 and PACS-2 on endosomes to down-regulate MHC-I. Mol Biol Cell 2012; 23: 2184-2197.

39. Schuurs-Hoeijmakers JH, Oh EC, Vissers LE, Swinkels ME, Gilissen C, Willemsen MA et al. Recurrent de novo mutations in PACS1 cause defective cranial-neural-crest migration and define a recognizable intellectual-disability syndrome. Am J Hum Genet 2012; 91: $1122-1127$.

40. Zainabadi K, Benyamini P, Chakrabarti R, Veena MS, Chandrasekharappa SC, Gatti RA et al. A 700-kb physical and transcription map of the cervical cancer tumor suppressor gene locus on chromosome 11q13. Genomics 2005; 85: 704-714.

41. Nalesnik MA, Tseng G, Ding Y, Xiang GS, Zheng ZL, Yu Y et al. Gene deletions and amplifications in human hepatocellular carcinomas: correlation with hepatocyte growth regulation. Am J Pathol 2012; 180: 1495-1508.

42. Mirza S, Rakha EA, Alshareeda A, Mohibi S, Zhao X, Katafiasz BJ et al. Cytoplasmic localization of alteration/deficiency in activation 3 (ADA3) predicts poor clinical outcome in breast cancer patients. Breast Cancer Res Treat 2013; 137: 721-731.

43. Sunde JS, Donninger H, Wu K, Johnson ME, Pestell RG, Rose GS et al. Expression profiling identifies altered expression of genes that contribute to the inhibition of transforming growth factor-beta signaling in ovarian cancer. Cancer Res 2006; 66: 8404-8412.

44. Ying MZ, Wang JJ, Li DW, Yu GZ, Wang X, Pan J et al. The p300/CBP associated factor: is frequently downregulated in intestinal-type gastric carcinoma and constitutes a biomarker for clinical outcome. Cancer Biol Ther 2009; 9: 312-320.

45. Ghizzoni M, Boltjes A, Graaf C, Haisma HJ, Dekker FJ. Improved inhibition of the histone acetyltransferase PCAF by an anacardic acid derivative. Bioorg Med Chem 2010; 18 : 5826-5834.

46. Sun J, Bird CH, Buzza MS, McKee KE, Whisstock JC, Bird PI. Expression and purification of recombinant human granzyme B from Pichia pastoris. Biochem Biophys Res Commun 1999; 261: 251-255.

47. Sedelies KA, Ciccone A, Clarke CJ, Oliaro J, Sutton VR, Scott FL et al. Blocking granulemediated death by primary human NK cells requires both protection of mitochondria and inhibition of caspase activity. Cell Death Differ 2008; 15: 708-717.

48. Dewson G, Kratina T, Czabotar P, Day CL, Adams JM, Kluck RM. Bak activation for apoptosis involves oligomerization of dimers via their alpha6 helices. Mol Cell 2009; 36: 696-703.

49. Brasacchio D, Okabe J, Tikellis C, Balcerczyk A, George P, Baker EK et al. Hyperglycemia induces a dynamic cooperativity of histone methylase and demethylase enzymes associated with gene-activating epigenetic marks that coexist on the lysine tail. Diabetes 2009; 58 : 1229-1236.

50. Waterhouse NJ, Sedelies KA, Browne KA, Wowk ME, Newbold A, Sutton VR et al. A central role for Bid in granzyme B-induced apoptosis. J Biol Chem 2005; 280: 4476-4482.

51. Waterhouse NJ, Trapani JA. A new quantitative assay for cytochrome $c$ release in apoptotic cells. Cell Death Differ 2003; 10: 853-855

52. Dewson G, Kratina T, Sim HW, Puthalakath H, Adams JM, Colman PM et al. To trigge apoptosis Bak exposes its $\mathrm{BH} 3$ domain and homo-dimerizes via $\mathrm{BH} 3$ :grooove interactions. Mol Cell 2008; 30: 369-380. 